\title{
Theoretical investigation for isomerization of allylic alcohols over $\mathrm{Au}_{6}$ cluster
}

\author{
K. Sakata ${ }^{1} \cdot$ H. Koga ${ }^{2}$ - T. Ishida ${ }^{3} \cdot$ J. Aimoto ${ }^{4}$. \\ M. Tokunaga ${ }^{4,5} \cdot$ M. Okumura ${ }^{1,2}$
}

Published online: 19 March 2015

(C) The Author(s) 2015. This article is published with open access at SpringerLink.com

\begin{abstract}
Transformation of allylic alcohols to corresponding saturated carbonyl compounds is one of the important reactions for industrial processes. Lately, Au-supported catalysts exhibit the catalytic activity for the isomerization of allylic alcohols to saturated aldehydes. However, the detail catalytic mechanism of this reaction was not elucidated in detail. Thus, theoretical calculations were carried out for the isomerization of 2-hexen-1-ol over isolated $\mathrm{Au}_{6}$ cluster in order to elucidate the reaction over Au catalysts. From these calculation results, it was found that the rate determining step of the reaction process was the hydrogen elimination from $\mathrm{OH}$ group of allylic alcohol, and the substrate was converted to 1-hexen-1-ol on $\mathrm{Au}_{6}$ cluster. Finally, it was also confirmed that 1-hexen-1ol was converted to the corresponding aldehyde, and its activation barrier was much smaller than that of the deprotonation from $\mathrm{OH}$ group of allylic alcohol.
\end{abstract}

Keywords DFT calculation - Au cluster catalyst . Isomerization · Allylic alcohol

M. Okumura

ok@chem.sci.osaka-u.ac.jp

1 Department of Chemistry, Graduate School of Science, Osaka University, 1-1 Machikaneyama, Toyonaka, Osaka 560-0043, Japan

2 Elements Strategy Initiative for Catalysts and Batteries (ESICB), Kyoto University, 1-30 Goryoohara, Kyoto 615-8245, Japan

3 Department of Applied Chemistry, School of Urban Environmental Sciences, Tokyo Metropolitan University, Tokyo, Japan

4 Department of Chemistry, Graduate School of Sciences, Kyushu University, 6-10-1 Hakozaki, Higashi-ku, Fukuoka 812-8581, Japan

5 International Research Center for Molecular Systems (IRCMS), Kyushu University, 744 Motooka, Nishi-ku, Fukuoka 819-0395, Japan

\section{Introduction}

Transformation of allylic alcohols to the corresponding saturated carbonyl compounds is one of the important reactions for chemical processes [1, 2]. While this conventional reaction contains a two-step sequential oxidation and reduction, isomerization of allylic alcohols enables single-step transformation. Therefore, various catalysts which contain $\mathrm{Ru}$ and $\mathrm{Rh}$ have been developed for this purpose [1-11]. Isomerization of allyl alcohol could also be used for a catalytic irreversible hydrolysis of allyl esters [3]. Though heterogeneous catalysts have been reported [12-17], they commonly use $\mathrm{H}_{2}$. However, as the presence of excess $\mathrm{H}_{2}$ promotes $\mathrm{C}=\mathrm{C}$ bond hydrogenation, saturated alcohols are produced. On the other hand, since Haruta and coworkers showed that gold-supported catalysts exhibit markedly high catalytic activity for $\mathrm{CO}$ oxidation at low temperatures [18-23], Au catalysts for several reactions have been paid much attention. Lately, Tsukuda et al. also showed that the $\mathrm{Au}$ nanoclusters stabilized by poly(N-vinyl-2-pyrrolidone) [PVP; $\left(\mathrm{C}_{6} \mathrm{H}_{9} \mathrm{ON}\right)_{\mathrm{n}}$ ], abbreviated to Au:PVP, can oxidize p-hydroxybenzyl alcohol selectively into the corresponding aldehyde in water without degradation [24]. This result suggests that Au cluster can present high catalytic activities without any metal oxide supports. For this catalysis by $\mathrm{Au}$, theoretical investigations have been carried out in order to elucidate the characteristics and reaction mechanism of Au cluster catalysts [25-27].

Recently, dehydrogenation of alcohol to aldehyde has been achieved even in the absence of $\mathrm{O}_{2}$ [28-30]. One-pot reactions with hydrogen-borrowing strategy over Au catalysts, in which hydrogen atoms produced by the initial dehydrogenation of alcohol are used for the next step reduction, have also appeared [31-34]. Lately, Tokunaga have attempted to apply this strategy for the Au-catalyzed isomerization of trans-2-octen1-ol to octanal [35]. However, the catalytic activity 
measurements do not reveal the role of $\mathrm{Au}$ cluster in $\mathrm{Au}$ supported catalysts in detail. Therefore, theoretical investigation for isomerization of trans-2-hexen-1-ol to hexanal by the isolated $\mathrm{Au}$ cluster was examined as a first step for understanding the isomerization of allylic alcohol over Au catalysts.

\section{Computational method}

In order to investigate the isomerization of trans-2-octen-1-ol to octanal catalyzed by Au clusters, $\mathrm{Au}_{6}$ cluster was used as a model system, because this cluster was the smallest cluster that has vertex and edge atoms. Trans-2-hexen-1-ol was used for the model substrate in order to reduce the computational costs. In all calculations, DFT with B3LYP functional was used. The scalar relativistic effective core potential (ECP) with double-zeta basis sets (SDD) for all gold atoms and 6-31+ $G(\mathrm{~d})$ basis sets were applied for the hydrogen, carbon, and oxygen atoms. All the geometries of the model cluster systems were fully optimized. Vibrational analysis was performed for the optimized geometries of the transition states and local minima. To characterize the stationary points, a frequency (a)

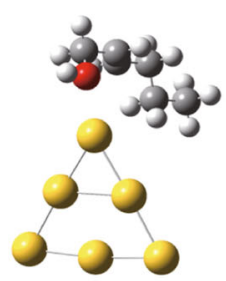

(f)

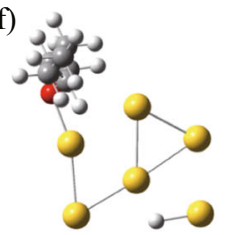

(k)

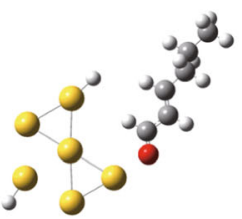

(p)

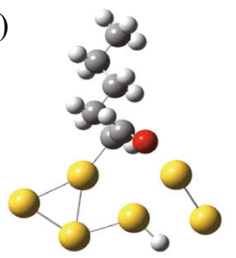

(u)

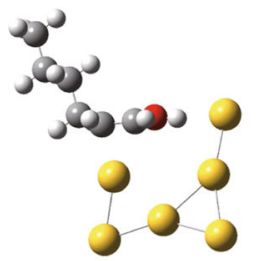

(b)

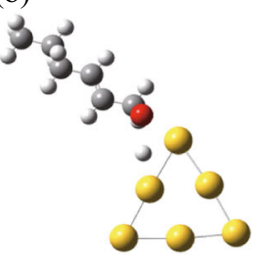

(g)

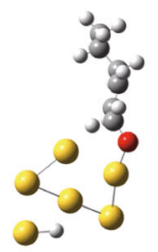

(1)

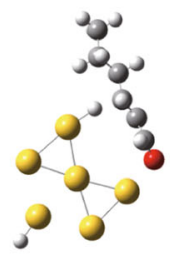

(q)

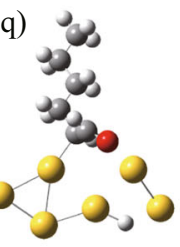

(v)

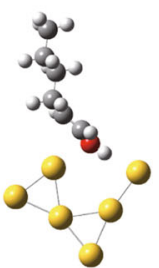

(c)

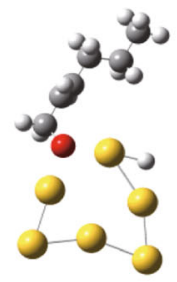

(h)
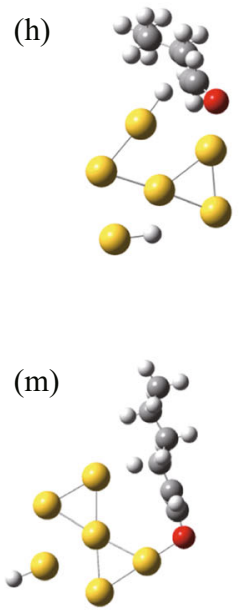

(r)

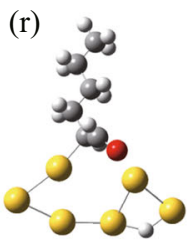

(w)

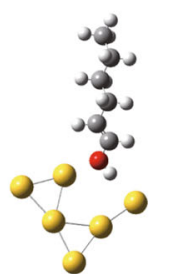

(d)

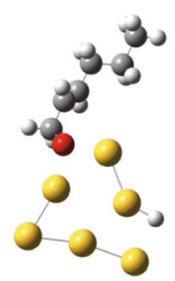

(e)

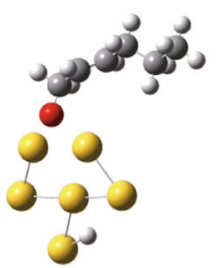

(i)

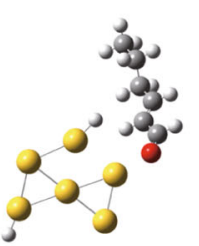

(j)

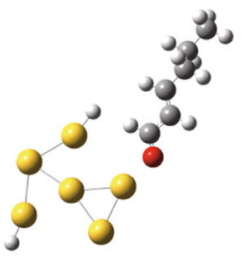

(n)

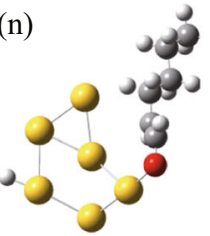

(s)

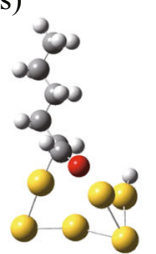

(x)

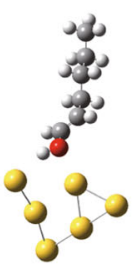

(o)

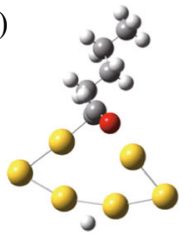

(t)

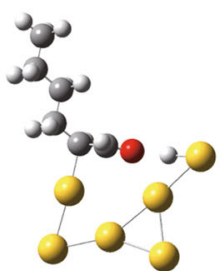

(y)

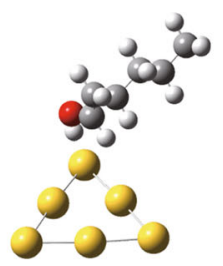

Fig. 1 The optimized geometries of a IM1, b TS1, c IM2, d TS2, e IM3, f TS3, g IM4, h TS4, i IM5, j TS5, k IM6, I TS6, m IM7, n TS7, o IM8, p TS8, q IM9, r TS9, s IM10, t TS10, u IM11, v TS11, w IM12, x TS12, and y IM13 


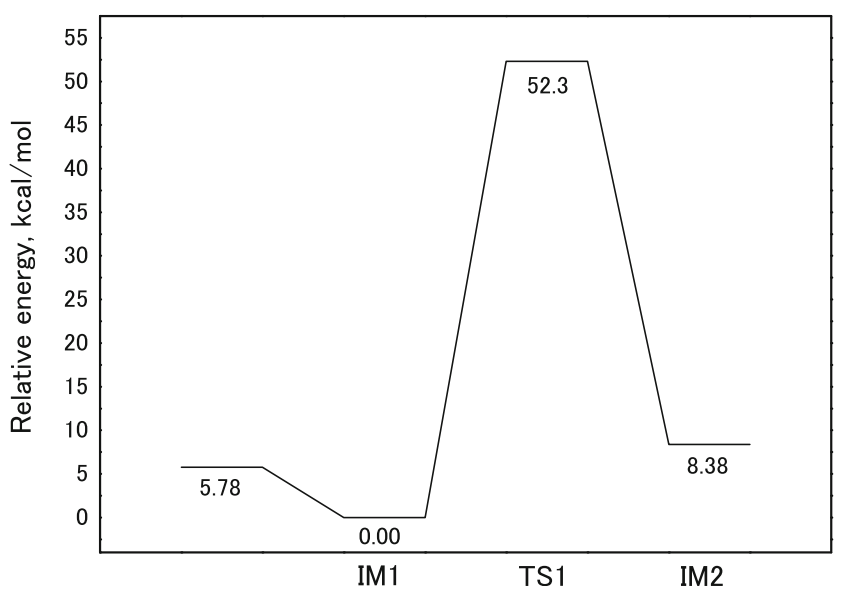

Fig. 2 The energy profile from IM1 to IM2. The energy profile was depicted by use of the sum of total energy and zero point energy

analysis was done for all stationary points at this level. To establish the relevant species, the intrinsic reaction coordinate (IRC) pathway was also run for all the transition states presented. The calculations were carried out using the Gaussian 09 software package [36].

\section{Result and discussion}

First of all, the interaction between $\mathrm{Au}_{6}$ and trans-2-hexen-1ol was investigated. The optimized structure was depicted in Fig. 1a. As shown in Fig. 1a, the substrate was adsorbed onto the vertex site of $\mathrm{Au}_{6}$ cluster, and its adsorption energy was $5.78 \mathrm{kcal} / \mathrm{mol}$. The first step of the isomerization of trans-2hexen-1-ol is the dehydrogenation from $\mathrm{OH}$ group of the substrate. The optimized structures and the obtained energy profile were also depicted in Fig. 1a-c and Fig. 2, respectively. From the calculation results, it was found that the activation

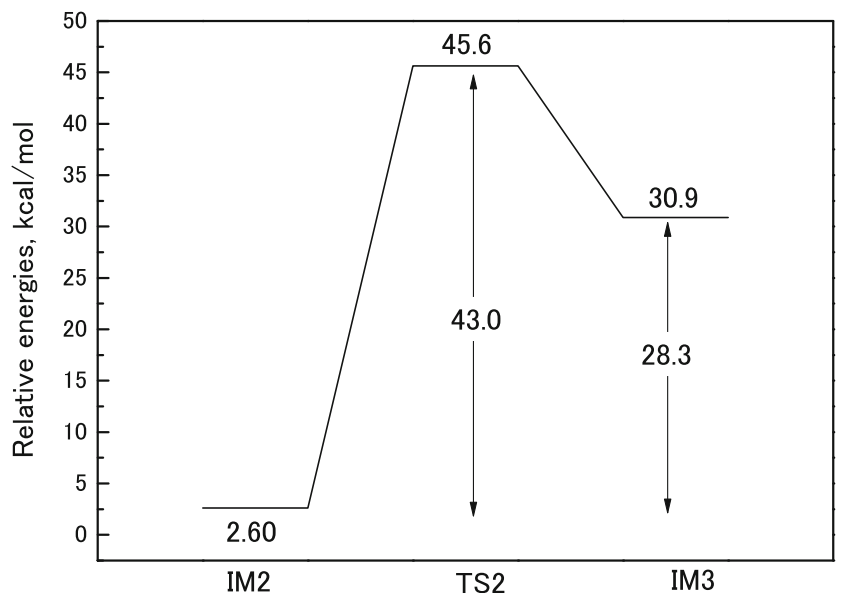

Fig. 3 The energy profile from IM2 to IM3. The energy profile was depicted by use of the sum of total energy and zero point energy

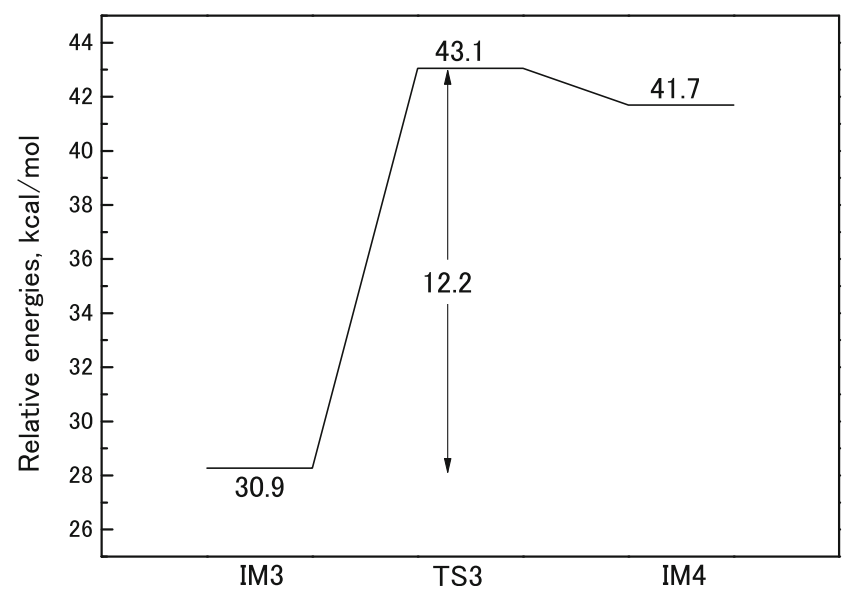

Fig. 4 The energy profile from IM3 to IM4. The energy profile was depicted by use of the sum of total energy and zero point energy

barrier of this reaction was $52.3 \mathrm{kcal} / \mathrm{mol}$, and the dissociated $\mathrm{H}$ and the residual substrate were adsorbed on the adjacent bridging sites of the vertex Au atom. In the second, hydrogen transfer processes proceeded on the model cluster. The calculation results were summarized in Fig. 1c-e and Fig. 3. The calculation results indicated that the activation energy of this process was $43.0 \mathrm{kcal} / \mathrm{mol}$, and the large deformation of $\mathrm{Au}_{6}$ cluster was presented. In the third, adsorption structure transformation of the residual substrate on $\mathrm{Au}_{6}$ cluster and the second hydrogen elimination process was examined. The results were shown in Fig. 1e-g and Fig. 4. The results indicated that the adsorption structure of the substrate was varied from $\mathrm{Au}-\mathrm{O}-\mathrm{Au}$ bridging type to $\mathrm{Au}-\mathrm{O}$ and $\mathrm{Au}-\mathrm{H}$ two site adsorption types, and the barrier of this process was $12.2 \mathrm{kcal} / \mathrm{mol}$. Successively, hydrogen of the first position $\mathrm{C}$ atom of the substrate was eliminated with a very small activation barrier as shown in Fig. 1g-i and Fig. 5. After this process, the deformation of $\mathrm{Au}_{6}$ cluster was presented. The optimized structures and the energy profile of this were shown in Fig. 1i-k

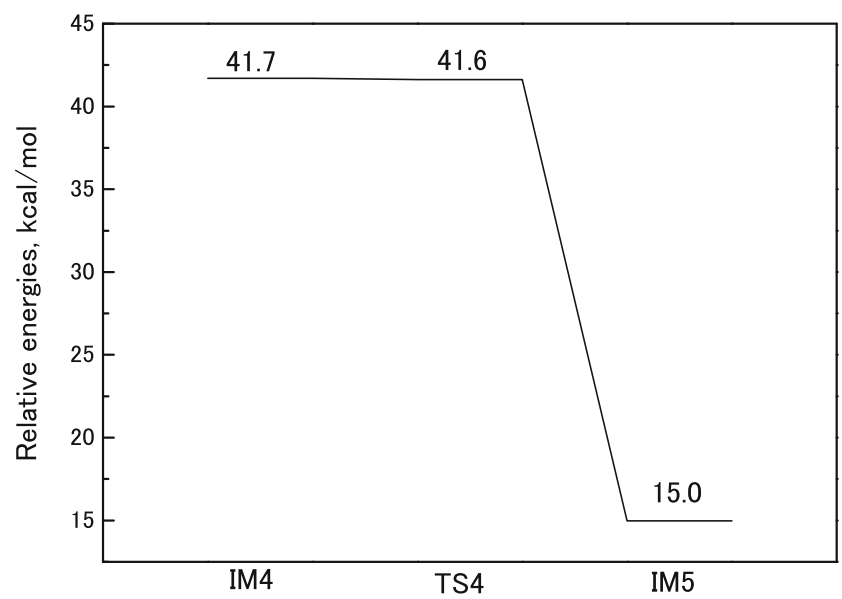

Fig. 5 The energy profile from IM4 to IM5. The energy profile was depicted by use of the sum of total energy and zero point energy 


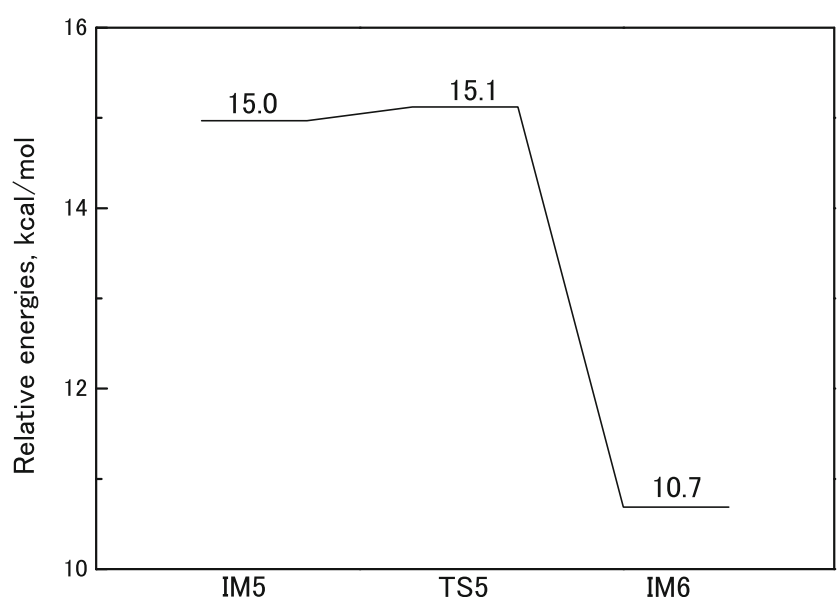

Fig. 6 The energy profile from IM5 to IM6. The energy profile was depicted by use of the sum of total energy and zero point energy

and Fig. 6. As shown in Fig. 6, the activation barrier of this step was small. After this step, the recombination between hydrogen and the substrate proceeded. In Fig. 1k-o and Fig. 7, the structures and the energy profile of this process were depicted. These processes showed that hydrogen was recombined with the third position $\mathrm{C}$ atom of the substrate, and the activation barrier of this reaction was $15.5 \mathrm{kcal} / \mathrm{mol}$. The large Au cluster deformation was also presented during hydrogen transfer in succession. Consequently, a relatively stable intermediate was obtained. As the final process of the isomerization, hydrogen transfer steps and second hydrogen recombination step on the model cluster were calculated. These structures were summarized in Fig. 1o-u. The calculated energy profile was depicted in Fig. 8. The results suggested that the activation barrier of the initial step of them was $33.0 \mathrm{kcal} / \mathrm{mol}$, and it was the largest among them though the activation barrier of the dehydration of $\mathrm{OH}$ group of the substrate was the largest. As shown in Fig. 1s, the structure of $\mathrm{Au}$ cluster in this step was transformed from 2D to 3D structure.

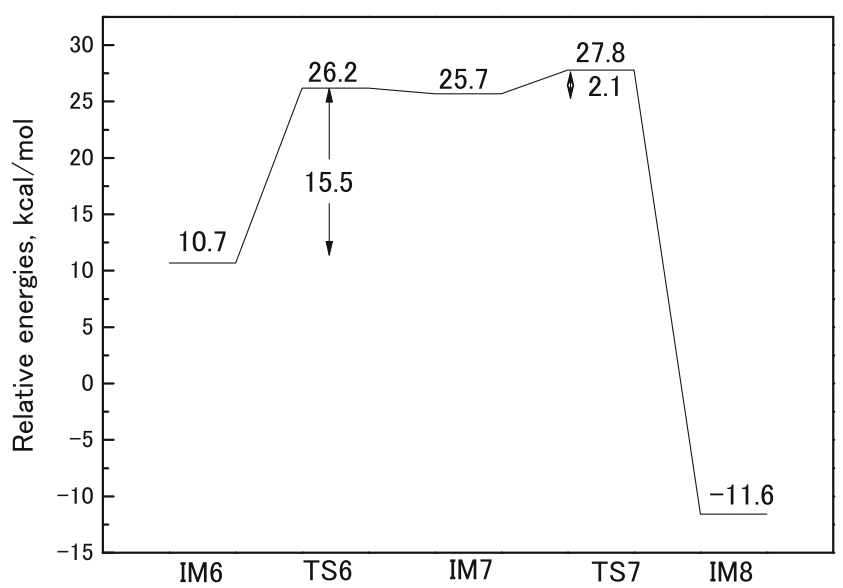

Fig. 7 The energy profile from IM7 to IM8. The energy profile was depicted by use of the sum of total energy and zero point energy

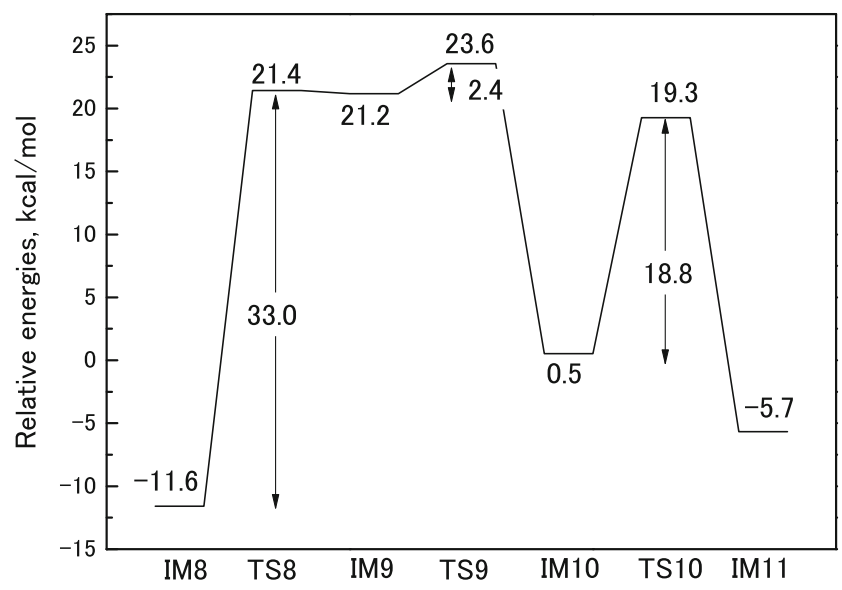

Fig. 8 The energy profile from IM8 to IM11. The energy profile was depicted by use of the sum of total energy and zero point energy

The remaining reaction step was the recombination of hydrogen atom with the substrate. The results for this step were also depicted in Fig. 8. This step also had the structure change of $\mathrm{Au}_{6}$ cluster and the recombination with hydrogen and the substrate. The activation energy of this step was $18.8 \mathrm{kcal} /$ $\mathrm{mol}$. In order to proceed the product desorption from Au cluster, the variation of the cluster structure must be needed as the $\mathrm{Au}_{6}$ cluster structure is largely distorted. They were also depicted in Fig. 1u-y and Fig. 9. These results indicated that the largest activation barrier for the structure variation of $\mathrm{Au}_{6}$ cluster was $16.8 \mathrm{kcal} / \mathrm{mol}$. Therefore, it could be concluded that the last hydrogen recombination step proceeded easily, and the product obtained on $\mathrm{Au}_{6}$ had enol form. Therefore, it could be presumed that keto-enol tautomerization would proceed. The calculation results indicated that the activation barrier of this tautomerization was $16.9 \mathrm{kcal} / \mathrm{mol}$, while six water molecules were added to the model system as hydration waters (Fig. 10). Additionally, the calculation results showed that the keto form of the substrate was stable than the enol form of

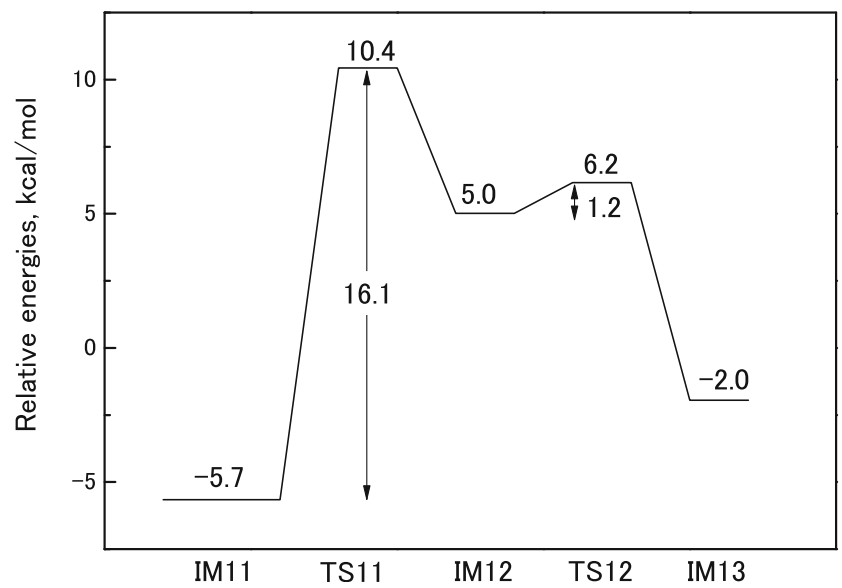

Fig. 9 The energy profile from IM11 to IM13. The energy profile was depicted by use of the sum of total energy and zero point energy 
Fig. 10 The optimized geometries and the energy difference for $\mathbf{a}$ enol form, bTS of keto-enol tautomerization, and $\mathbf{c}$ keto form of 3-hexen-1-ol (a)

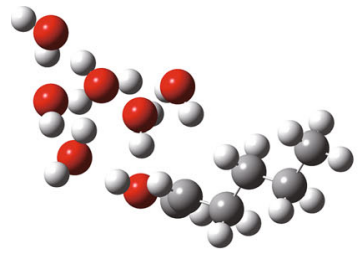

0.0 (b)

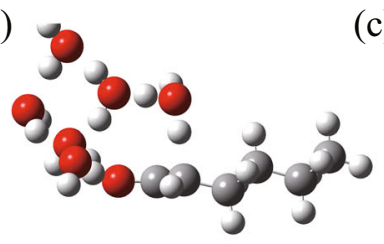

18.9 (c)

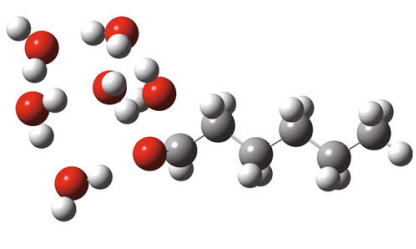

$-7.4$ this. From these calculations, it was found that the isomerization from allylic alcohol to the corresponding aldehyde over Au cluster catalyst could proceed by using both dehydrogenation and hydrogenation processes, while the initial dehydrogenation step was a difficult step. Finally, it could be concluded that the rate determining step of the isomerization of trans-2-hexen-1-ol over $\mathrm{Au}_{6}$ cluster was the initial dehydrogenation from $\mathrm{OH}$ group of trans-2-hexen-1-ol, and the corresponding enol was produced. In order to reduce the activation barrier of the rate determining step, cationic $\mathrm{Au}_{6}$ cluster was also investigated. However, the calculation results showed that the activation barrier of dehydrogenation from $\mathrm{OH}$ group of trans-2-hexen-1-ol over $\mathrm{Au}_{6}{ }^{+}$cluster was $49.4 \mathrm{kcal} / \mathrm{mol}$. While the activation barrier of the rate determining step of this reaction was reduced slightly, the absolute value of this activation barrier is still large, and the effect of the charge variation of $\mathrm{Au}_{6}$ for the reaction is small. In this calculation, $\mathrm{Au}_{6}$ cluster was only used, while the size effect of Au cluster was one of the most important factors for the generation of catalysis by Au. While it would be deduced that the absolute values of the activation barriers for each elemental reaction step would be varied depending on the size of $\mathrm{Au}$ cluster, the trend of the rate determining step would be the same. This is because the activation barrier of the rate determining step in this reaction is largest among those of the reaction steps, and a certain metal oxide support is indispensable to the isomerization reaction over Au catalysts in the experiments. Therefore, it could be presumed that the calculation results showed the general trend of isomerization of allylic alcohols over isolated Au cluster catalysts. Additionally, all the calculations for the model clusters were carried out in a vacuum condition. In the real condition system, $\mathrm{Au}$ catalysts and substrates are surrounded by organic solvent molecules, as the reaction proceeds in a select organic solvent. Therefore, the solvent effect by use of the organic solvent molecule for the isomerization of allylic alcohols over $\mathrm{Au}$ cluster catalysts has to be considered for the further investigation of this. Moreover, it is well known that the basic condition promotes dehydrogenation from the $\mathrm{OH}$ group of glucose and enhanced reaction rate of the aerobic oxidation of glucose over polymer-stabilized
Au cluster catalysts. However, the isomerization reaction proceeds in organic solvents. Therefore, it is difficult to use bases for this catalytic reaction. This means that the polymer-stabilized Au cluster catalysts would not be suitable for this reaction as the electronic states of these catalysts prepared are almost neutral or anionic, and its high catalytic activities are presented at basic conditions. Thus, these results suggested that the additional material, such as metal oxide supports, other precious metals, etc., must be needed as an active site for the initial dehydrogenation from $\mathrm{OH}$ group of trans-2-hexen-1-ol reaction, as the isolated $\mathrm{Au}$ clusters were not suitable for the initial dehydrogenation from $\mathrm{OH}$ group of trans-2-hexen-1ol reaction. In order to investigate this isomerization reaction over $\mathrm{Au}$ catalysts, theoretical investigation for the hetero-junction between $\mathrm{Au}$ cluster and the select metal oxide supports which were suitable for the dehydrogenation from $\mathrm{OH}$ group of allylic alcohol must be considered in the next step.

\section{Conclusions}

In this manuscript, a theoretical study on isomerization of allylic alcohol over $\mathrm{Au}_{6}$ cluster was reported. The isolated $\mathrm{Au}_{6}$ cluster was used as a model catalyst in order to investigate the nature of $\mathrm{Au}$ cluster itself. Theoretical calculation results showed that the rate determining step of the reaction process was the dehydrogenation from $\mathrm{OH}$ group of allylic alcohol, 2-hexen-1-ol, and the product obtained was corresponding enol (1-hexen-1-ol). Finally, it was also confirmed that 1-hexen-1-ol was converted to the corresponding aldehyde, and its activation barrier was much smaller than that of the dehydrogenation from $\mathrm{OH}$ group of allylic alcohol. Therefore, it could be concluded that it was possible to transform the aldehyde form allylic alcohols on $\mathrm{Au}_{6}$ cluster, though the initial dehydrogenation from $\mathrm{OH}$ group of allylic alcohol had relatively large activation barrier. In order to reduce the activation barrier of the rate determining step and rationalize the total reaction processes, the introduction of the select metal oxide supports that are suitable for this reaction must be needed. 
Acknowledgments This work was financially supported by Japan Science and Technology Agency (JST), ALCA.

Open Access This article is distributed under the terms of the Creative Commons Attribution License which permits any use, distribution, and reproduction in any medium, provided the original author(s) and the source are credited.

\section{References}

1. Uma R, Crévisy C, Grée R (2003) Transposition of allylic alcohols into carbonyl compounds mediated by transition metal complexes. Chem Rev 103:27-52. doi:10.1021/cr0103165

2. van der Drift RC, Bouwman E, Drent E (2002) Homogeneously catalysed isomerisation of allylic alcohols to carbonyl compounds. J Organomet Chem 650:1-24. doi:10.1016/S0022-328X(02) 01150-6

3. Nakamura A, Hamasaki A, Goto S, Utsunomiya M, Tokunaga M (2011) Irreversible catalytic ester hydrolysis of allyl esters to give acids and aldehydes by homogeneous ruthenium and ruthenium/ palladium dual catalyst systems. Adv Synth Catal 353:973-984. doi:10.1002/adsc.201000369

4. Servin P, Laurent R, Dib H, Gonsalvi L, Peruzzini M, Majoral JP, Caminade AM (2012) New synthesis of carbazole-1,4-quinone using a tandem ring-closing metathesis and dehydrogenation reaction under oxygen atmosphere, and its application to the synthesis of murrayaquinone A. Tetrahedron Lett 53:3876-3878. doi:10. 1016/j.tetlet.2011.05.066

5. Zharmagambetova AK, Ergozhin EE, Sheludyakov YL, Mukhamedzhanova SG, Kurmanbayeva IA, Selenova BA, Utkelov BA (2001) 2-Propen-1-ol hydrogenation and isomerisation on polymer-palladium complexes - effect of polymer matrix. J Mol Catal A Chem 177:165-170. doi:10.1016/S13811169(01)00316-8

6. Servin P, Laurent R, Gonsalvi L, Tristany M, Peruzzini M, Majoral JP, Caminade AM, (2009) Grafting of water-soluble phosphines to dendrimers and their use in catalysis: positive dendritic effects in aqueous media. Dalton Trans 4432-4434. doi:10.1039/B906393P

7. Menéndez-Rodríguez L, Crochet P, Cadierno V (2013) Catalytic isomerization of allylic alcohols promoted by complexes

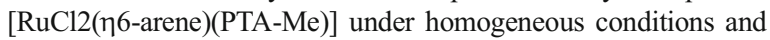
supported on Montmorillonite K-10. J Mol Catal A Chem 366: 390-399. doi:10.1016/j.molcata.2012.10.025

8. Corkum EG, Kalapugama S, Hass MJ, Bergans SH (2012) Solventfree isomerization of allylic alcohols catalyzed by a rhodium catalyst-organic framework. RSC Adv 2:3473-3476. doi:10.1039/ C2RA20197F

9. Ito $\mathrm{M}$, Kitahara $\mathrm{S}$, Ikariya $\mathrm{T}(2005) \mathrm{Cp} * \mathrm{Ru}(\mathrm{PN})$ complex-catalyzed isomerization of allylic alcohols and its application to the asymmetric synthesis of muscone. J Am Chem Soc 2005(127):6172-6173. doi:10.1021/ja050770g

10. Tanaka K, Qiao S, Tobisu M, Lo MMC, Fu GC (2000) Enantioselective isomerization of allylic alcohols catalyzed by a rhodium/phosphaferrocene complex. J Am Chem Soc 122:98709871. doi:10.1021/ja002471r

11. Tanaka K, Fu GC (2001) A versatile new catalyst for the enantioselective isomerization of allylic alcohols to aldehydes: scope and mechanistic studies. J Org Chem 66:8177. doi:10. 1021/jo010792v

12. Musolino MG, De Maio P, Donato A, Pietropaolo R (2004) Hydrogenation versus isomerization in $\alpha, \beta$-unsaturated alcohols reactions over $\mathrm{Pd} / \mathrm{TiO} 2$ catalysts. J Mol Catal A Chem 208:219 224. doi:10.1016/j.molcata.2003.07.008
13. Kim JW, Koike T, Kotani M, Yamaguchi K, Mizuno N (2008) Synthetic scope of $\mathrm{Ru}(\mathrm{OH})_{\mathrm{x}} / \mathrm{Al}_{2} \mathrm{O}_{3}$-catalyzed hydrogen-transfer reactions: an application to reduction of allylic alcohols via a sequential process of isomerization/meerwein-ponndorf-verley-type reduction. Chem Eur J 14:4104-4109. doi:10.1002/chem.200701917

14. Sadeghmoghaddam E, Lam C, Choi D, Shon YS (2011) Synthesis and catalytic properties of alkanethiolate-capped $\mathrm{Pd}$ nanoparticles generated from sodium $S$-dodecylthiosulfate. J Mater Chem 21: 307-312. doi:10.1039/C0JM01761B

15. Sadeghmoghaddam E, Gaïeb K, Shon YS (2011) Catalytic isomerization of allyl alcohols to carbonyl compounds using poisoned $\mathrm{Pd}$ nanoparticles. Appl Catal A 405:137-141. doi:10.1016/j.apcata. 2011.07.038

16. Sadeghmoghaddam E, Gu H, Shon YS (2012) Pd nanoparticlecatalyzed isomerization vs hydrogenation of allyl alcohol: solvent-dependent regioselectivity. ACS Catal 2:1838-1845. doi: $10.1021 / \operatorname{cs} 300270 d$

17. Moreno M, Kissell LN, Jasinski JB, Zamborini FP (2012) Selectivity and reactivity of alkylamine- and alkanethiolatestabilized Pd and PdAg nanoparticles for hydrogenation and isomerization of allyl alcohol. ACS Catal 2:2602-2613. doi:10.1021 cs300361y

18. Haruta M, Kobayashi T, Sano H, Yamada N (1987) Chem Lett 405

19. Haruta M, Yamada N, Kobayashi T, Iijima S (1989) Gold catalysts prepared by coprecipitation for low-temperature oxidation of hydrogen and of carbon monoxide. J Catal 115:301-309. doi:10.1016/ 0021-9517(89)90034-1

20. Haruta M, Tsubota S, Kobayashi T, Kageyama H, Genet MJ, Delmon B (1993) Low-temperature oxidation of CO over gold supported on $\mathrm{TiO}_{2}, \alpha-\mathrm{Fe}_{2} \mathrm{O}_{3}$, and $\mathrm{Co}_{3} \mathrm{O}_{4}$. J Catal 144:175-192. doi:10.1006/jcat.1993.1322

21. Okumura M, Nakamura S, Tsubota S, Nakamura T, Azuma M, Haruta M (1998) Chemical vapor deposition of gold on $\mathrm{Al}_{2} \mathrm{O}_{3}$, $\mathrm{SiO}_{2}$, and $\mathrm{TiO}_{2}$ for the oxidation of $\mathrm{CO}$ and of $\mathrm{H}_{2}$. Catal Lett 51: 53-58. doi:10.1023/a:1019020614336

22. Takei T, Akita T, Nakamura I, Fujitani T, Okumura M, Okazaki K, Huang J, Ishida T, Haruta M (2012) Heterogeneous catalysis by gold. Adv Catal 55:1-126. doi:10.1016/B978-0-12-385516-9. 00001-6

23. Taketoshi A, Haruta M (2014) Size- and structure-specificity in catalysis by gold clusters. Chem Lett 43:380-387. doi:10.1246/cl. 131232

24. Tsunoyama H, Sakurai H, Negishi Y, Tsukuda T (2005) Sizespecific catalytic activity of polymer-stabilized gold nanoclusters for aerobic alcohol oxidation in water. J Am Chem Soc 127: 9374-9375. doi:10.1021/ja052161e

25. Okumura M, Kitagawa Y, Kawakami T, Haruta M (2008) Theoretical investigation of the hetero-junction effect in PVPstabilized Au13 clusters. The role of PVP in their catalytic activities. Chem Phys Lett 459:133-136. doi:10.1016/j.cplett.2008.04. 120

26. Sakata K, Tada K, Yamada S, Kitagawa Y, Kawakami T, Yamanaka S, Okumura M (2014) DFT calculations for aerobic oxidation of alcohols over neutral $\mathrm{Au}_{6}$ cluster. Mol Phys 112:385-392. doi:10. 1080/00268976.2013.828857

27. Karanjit S, Bobuatong K, Fukuda R, Ehara M, Sakurai H (2013) Mechanism of the aerobic oxidation of methanol to formic acid on Au8-: a DFT study. Int J Quant Chem 113:428-436. doi:10.1002/ qua. 24056

28. Fang W, Chen J, Zhang Q, Deng W, Wang Y (2011) Hydrotalcitesupported gold catalyst for the oxidant-free dehydrogenation of benzyl alcohol: studies on support and gold size effects. Chem Eur J 17:1247-1256. doi:10.1002/chem.201002469

29. Fang W, Zhang Q, Chen J, Deng W, Wang Y (2010) Gold nanoparticles on hydrotalcites as efficient catalysts for oxidant-free 
dehydrogenation of alcohols. Chem Commun 46:1547-1549. doi: 10.1039/B923047E

30. Shimizu KI, Kon K, Shimura K, Hakim SSMA (2013) Acceptor-free dehydrogenation of secondary alcohols by heterogeneous cooperative catalysis between $\mathrm{Ni}$ nanoparticles and acid-base sites of alumina supports. J Catal 300:242-250. doi:10.1016/j.jcat.2013.01.005

31. Su FZ, He L, Ni J, Cao Y, He HY, Fan KN (2008) Efficient and chemoselective reduction of carbonyl compounds with supported gold catalysts under transfer hydrogenation conditions. Chem Commun 3531-3533. doi:10.1039/B807608A

32. Ishida T, Kawakita N, Akita T, Haruta M (2009) One-pot N-alkylation of primary amines to secondary amines by gold clusters supported on porous coordination polymers. Gold Bull 42:267-274. doi:10.1007/BF03214948

33. Ishida T, Takamura R, Takei T, Akita T, Haruta M (2012) Support effects of metal oxides on gold-catalyzed one-pot $\mathrm{N}$-alkylation of amine with alcohol. Appl Catal A 413-414:261-266. doi:10.1016/ j.apcata.2011.11.017

34. Liu X, Ding RS, He L, Liu YM, Cao Y, He HY, Fan KN (2013) C-C cross-coupling of primary and secondary benzylic alcohols using supported gold-based bimetallic catalysts. ChemSusChem 6:604608. doi:10.1002/cssc.201200804
35. Ishida T, Imoto J, Hamasaki A, Ohashi H, Honma T, Yokoyama T, Sakata K, Okumura M, Tokunaga M (2014) Formation of gold clusters on La-Ni mixed oxides and its catalytic performance for isomerization of allylic alcohols to saturated aldehydes. Chem Lett 43:1368-1370. doi:10.1246/cl.140369

36. Gaussian 09, Revision D.01, Frisch MJ, Trucks GW, Schlegel HB, Scuseria GE, Robb MA, Cheeseman JR, Scalmani G, Barone V, Mennucci B, Petersson GA, Nakatsuji H, Caricato M, Li X, Hratchian HP, Izmaylov AF, Bloino J, Zheng G, Sonnenberg JL, Hada M, Ehara M, Toyota K, Fukuda R, Hasegawa J, Ishida M, Nakajima T, Honda Y, Kitao O, Nakai H, Vreven T, Montgomery JA Jr, Peralta JE, Ogliaro F, Bearpark M, Heyd JJ, Brothers E, Kudin KN, Staroverov VN, Kobayashi R, Normand J, Raghavachari K, Rendell A, Burant JC, Iyengar SS, Tomasi J, Cossi M, Rega N, Millam MJ, Klene M, Knox JE, Cross JB, Bakken V, Adamo C, Jaramillo J, Gomperts R, Stratmann RE, Yazyev O, Austin AJ, Cammi R, Pomelli C, Ochterski JW, Martin RL, Morokuma K, Zakrzewski VG, Voth GA, Salvador P, Dannenberg JJ, Dapprich S, Daniels AD, Farkas Ö, Foresman JB, Ortiz JV, Cioslowski J, Fox DJ, Gaussian, Inc., Wallingford CT, (2009) 